purposively selected from a range of socio-economic backgrounds. Semi-structured interviews were completed with eleven parents (nine mothers; two fathers) in parents' homes. Transcripts were analysed using thematic analysis.

Results Two themes were developed from analysis. 'Quality of communication' describes how parents develop confidence in the SALT and open communication. 'Shared responsibility' describes how parents felt supported by and jointly responsible with the SALT in helping their child. Elements of the interaction that may help SALTs engage parents more fully are: sharing expertise freely, communicating information clearly, demonstrating understanding of the parents' perspective, treating the parent as an equal, encouraging open dialogue, supporting parents, showing genuine interest in the child and providing personalised and achievable therapy advice.

Conclusion and implications for clinical practice This study has increased understanding of how SALTs can work with parents to optimise engagement. SALTs can consider elements of the parent-SALT interaction that they may need to demonstrate more fully to engage parents with therapy. Future studies could measure and evaluate these elements.

\section{P16 CANCER SURVIVORS' EXPERIENCE WITH TELEHEALTH: A SYSTEMATIC REVIEW AND THEMATIC SYNTHESIS}

${ }^{1}$ Anna Cox, ${ }^{2}$ Grace Lucas, ${ }^{1}$ Afrodita Marcu, ${ }^{1}$ Wendy Grosvenor, ${ }^{1}$ Freda Mold, ${ }^{3}$ Roma Maguire, ${ }^{1}$ Marianne Piano, ${ }^{1}$ Emma Ream. ' ${ }^{1}$ University of Surrey, Guildford, UK; ${ }^{2}$ City University, London, UK; ${ }^{3}$ University of Strathclyde, Glasgow, UK

\subsection{6/bmjopen-2019-QHRN.51}

Background There is a drive to transfer the care of cancer survivors to the community and encourage them to play an active role in their own care. Telehealth is an important contributor to this evolving model of care but we are lacking an integrative perspective and in-depth understanding of how cancer survivors accept it, engage with it, and benefit from it.

Objective To systematically identify, appraise, and synthesize qualitative research evidence on the experiences of adult cancer survivors participating in telehealth interventions, to characterize the patient experience of telehealth interventions for this group.

Methods We searched PsycINFO, Medline, CINAHL, Embase, and Cochrane Central Register of Controlled Trials for studies published in English between 2006 and 2016 reporting qualitative data (including verbatim quotes) on adult cancer survivors' experience of participating in a telehealth care intervention (defined as remote communication or remote monitoring with a health care professional delivered by telephone, Internet, or hand-held or mobile technology). All papers underwent inductive analysis, involving comparison, reexamination, and grouping of codes to develop descriptive themes. Analytical themes were developed through an iterative process of reflection on, and interpretation of, the descriptive themes within and across studies.

Results Across 22 papers included in the review, three analytical themes emerged, each with three descriptive subthemes: (1) influence of telehealth on the disrupted lives of cancer survivors (convenience, independence, and burden); (2) personalized care across physical distance (time, space, and the human factor); and (3) remote reassurance-a safety net of health care professional connection (active connection, passive connection, and slipping through the net). Telehealth interventions represent a convenient approach to cancer care, which can potentially minimise treatment burden and disruption to cancer survivors' lives.

Conclusions Telehealth interventions can engender an experience of personalised care, while providing cancer survivors with independence and reassurance.

\section{P17 ADOPTING THE NOMINAL GROUP TECHNIQUE TO UNDERSTAND THE USE OF RELIGIOUS PRACTICES AND EXPERIENCES}

${ }^{1}$ Ophelia Anarfi, ${ }^{2}$ Stella Dzifa Monu, ${ }^{1,3}$ Charles Christopher Mate-Kole. ${ }^{1}$ Department of Psychology, University of Ghana-Legon, Accra-Greater Accra Region, Ghana; ${ }^{2}$ Korle-Bu Teaching Hospital, Accra, Ghana; ${ }^{3}$ Centre for Aging Studies, University of Ghana, AccraLegon, Ghana

\subsection{6/bmjopen-2019-QHRN.52}

Background Religion plays a vital role in recovery of illness of which stroke is not an exception.

Aims/Objectives To determine the various and use of religious experiences and practices adopted as a recovery strategy in the face of stroke condition.

Methods 20 participants would be recruited from the Stroke Unit and the Physiotherapy Unit of the Korle-Bu Teaching Hospital (KBTH to participate in two Nominal Group Technique (NGT) meeting. Stroke survivors from the first group would be asked to generate list of religious practices and experiences in response to the question 'What are the religious practices, values and beliefs that are related to the culture which aids in recovery after stroke?'; and the second group would be asked to generate responses relating to the impact of religion 'What are the positive and negative impact of religion to health and recovery after stroke?'

Expected results It should be expected that the topmost religious practices and experiences that relate to recovery after stroke would include reading of scriptures and recitation of mantra, prayers and fasting, consultation and directions from pastors, and meditation. The topmost impact of religion on recovery may include issues with adherence to treatment, resorting to alternative forms of treatment, and healershopping.

Conclusion Most of the religious practices and experiences were considered to aid in recovery after stroke. On the other hand, although there are positive aspects of religion on health, there are negative aspects of it that worsens the recovery after stroke.

\section{P18 DESIGNING FOR WELL-BEING: THE INFLUENCE OF A SCHOOLYARD INTERVENTION ON SUBJECTIVE WELL-BEING}

${ }^{1}$ Matluba Khan, ${ }^{2}$ Sarah McGeown. ${ }^{1}$ University College London, London, UK; ${ }^{2}$ University of Edinburgh, Edinburgh, UK

\subsection{6/bmjopen-2019-QHRN.53}

This study examines effects of a schoolyard intervention on primary school children's perceived motivation, exploration, peer-relation, teaching and learning in Bangladesh. $43 \%$ of the children in developing countries grow with poorer mental development. More than $21 \%$ of children leave primary 
school before completion in Bangladesh which negatively influences their mental well-being. The study adopted a quasi-experimental action evaluation strategy to investigate the role of an improved school landscape on children's subjective well-being. A Government primary school ground in Bangladesh was co-designed and developed which was used as a context and tool for formal teaching and informal play. The intervention included participatory design and development of the school ground, use of the school ground for learning of formal curriculum and also for informal play that took place between November 2014 and May 2015. Focus groups discussion were conducted with children $(n=29)$, teachers $(n=11)$ and parents $(n=6)$ both before and after the intervention in order to understand whether and how a designed environment can have an impact on children's teaching, learning and well-being. Semi-structured interviews were conducted with teachers $(n=2)$ who led children outdoors for teaching of science and mathematics. The findings suggest that the new schoolyard offered increased opportunities for exploration of the environment, physical activity and interaction with peers which positively influenced children's well-being.

\section{P19 THEMATIC ANALYSIS OF PLAYERS' REVIEWS OF VIRTUAL REALITY EXERGAMES}

${ }^{1}$ Nuša Farič, ${ }^{1}$ Henry Potts, ${ }^{2}$ Adrian Hon, ${ }^{3}$ Lee Smith, ${ }^{4}$ Katie Newby, ${ }^{1}$ Andrew Steptoe, ${ }^{1}$ Abi Fisher. ${ }^{1}$ University College London, London, UK; ${ }^{2}$ Six to Start, London, UK; ${ }^{3}$ Anglia Ruskin University, Cambridge, UK; ${ }^{4}$ Coventry University, Coventry, UK

\subsection{6/bmjopen-2019-QHRN.54}

Background Physical activity is associated with a variety of physical and psychosocial health benefits, but levels of moderate-to-vigorous intensity physical activity remain low worldwide. The application of virtual reality (VR) gaming systems involving movement (VR exergames) to promote physical activity is a promising avenue for engaging people in more physical activity. The aim of this study was to synthesise public reviews of popular VR exergames to identify common features that players like or disliked in order to inform future VR exergame design.

Methods We conducted a thematic analysis of 465 reviews of the 31 most popular exergames sold in the top three VR marketplaces, Steam, Viveport and Oculus. We identified the most common themes using thematic analysis.

Results The reviews were mixed, reporting a great variety of expectations, preferences and gaming experiences. Players preferred games that were highly realistic (e.g. closely simulate real-world sport), intuitive (in terms of the body movement and controls), and games that provided step-by-step increases in skill acquisition. Music was reported as greatly enhancing the experience. Favoured were social aspects with multiplayer options for company with friends or help from experienced players. Reviewers consistently reported that they felt VR exergaming was providing a high level of exertion equivalent to real world exercise, and the immersion/enjoyment was a welcome distraction from the exertion. There were three themes in negative reviews: the first was around bugs that rendered games frustrating. The quality of graphics had a particularly strong impact on perceived enjoyment. Reviewers disliked when games had overly complex controls and display functions that evoke motion sickness.
Conclusions VR exergames prove a stimulating way to engage in physical activity and a way to distract from negative perceptions of performing exercise. Future research calls for designing games that will stimulate the players in a realistic, intuitive, gradual step-wise way while meeting players' needs.

\section{P20 RATIONALITIES OF POSTPONING SCREENING: WOMEN'S INTERPRETATIONS OF CANCER RISKS AND PREVENTION}

${ }^{1}$ Gunvor Aasbø, ${ }^{2}$ Kari Nyheim Solbrække. ${ }^{1}$ Cancer registry of Norway, Oslo, Norge, Norway; ${ }^{2}$ Institute of Health and Society, University of Oslo, Oslo, Norway

\subsection{6/bmjopen-2019-QHRN.55}

Background In mainstream public health theory and praxis, citizens' ability to comply to healthy and preventative behaviour is often interpreted to be a question of knowledge. However, knowledge is complex, including a blend of scientific and medical knowledge, cultural attitudes, individual convictions and ignorance, in addition to personal uncertainties. Thus, in the context of cervical screening attendance, social constructions of knowledge play a pivotal role in the articulation of rationalities towards screening attendance.

Aim To generate a critical understanding of the social construction of knowledge about cervical cancer risks and prevention, in order to better understand why women in Norway may postpone cervical screening.

Methods We have completed 11 focus group interviews (FGI's) in Norway. In nine of the FGI, women who had postponed cervical screening participated. The FGI centred around six statements about cervical screening attendance.

Results Two important controversies were prominent in women's reflection about cervical cancer risk and prevention. First, cervical cancer was throughout the discussions understood as randomly acquired, but risk was modified by lifestyle, stress, genetics, and sexual risk behaviour. Secondly, women reflected conflicting views on the purpose of screening. Screening was mainly understood as diagnostic, and to less degree as prevention and for data-gathering purposes. In further analysis, we analyse how these different opinions are linked to attitudes of cancer fatalism and cancer fear, as well as cancer stigma and blame.

Conclusion Construction of knowledge of cancer risk and prevention has significance for understanding ambivalence regarding screening attendance in Norway.

\section{P21 'MY IDENTITY HAD JUST BEEN COMPLETELY DEVASTATED' - EXPERIENCES OF ADOLESCENT AND YOUNG ADULTS WITH}

${ }^{1}$ Ana Martins, ${ }^{2}$ Lindsey Bennister, ${ }^{1}$ Lorna Fern, ${ }^{3}$ Craig Gerrand, ${ }^{2}$ Maria Onasanya, ${ }^{4}$ Lesley Storey, ${ }^{5}$ Mary Wells, ${ }^{3}$ Julie Woodford, ${ }^{1}$ Rachael Windsor, ${ }^{1}$ Jeremy Whelan, ${ }^{1}$ Rachel Taylor. 'University College London Hospitals NHS Foundation Trust, London, UK; ${ }^{2}$ Patient Representative, UK; ${ }^{3}$ Royal National Orthopaedic Hospital, Stanmore, UK; ${ }^{4}$ Queens University Belfast, Belfast, UK; ${ }^{5}$ Imperial College Healthcare NHS Trust, London, UK

\subsection{6/bmjopen-2019-QHRN.56}

Background Treatment of sarcoma often involves long-term hospitalisation, extensive surgery, loss of mobility, complex rehabilitation programmes, and is in many cases accompanied by low expectations of survival. Subsequently, poorer patient- 